\title{
X-Rays Response of Diamond Detectors Constructed Using Diamond Layers Produced by Low Power Microwave Chemical Vapor Deposition Reactor
}

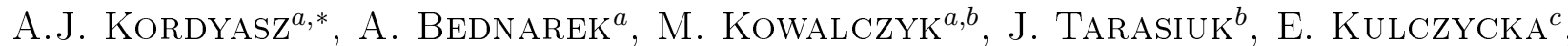

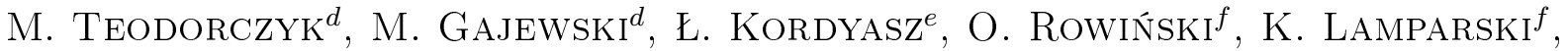 \\ E. KARWAŃSKI ${ }^{f}$, T. LIPCZEWSKI ${ }^{f}$ \\ ${ }^{a}$ Heavy Ion Laboratory, Warsaw University, L. Pasteura 5a, 02-093 Warsaw, Poland \\ ${ }^{b}$ Institute of Experimental Physics, University of Warsaw, L. Pasteura 5a, 02-093 Warsaw, Poland \\ ${ }^{c}$ National Centre for Nuclear Research, A. Sołtana 7, 05-400 Otwock, Poland \\ ${ }^{d}$ Institute of Electronic Materials Technology, Wólczyńska 133, 01-919 Warsaw, Poland \\ ${ }^{e}$ Warsaw University of Technology, Faculty of Mechatronics, Institute of Micromechanics and Photonics, \\ Department of Design of Precision Devices, Warsaw, Poland \\ ${ }^{f}$ Medical University of Warsaw, S. Banacha 1, 02-097 Warsaw, Poland
}

\begin{abstract}
The low power reactor for microwave chemical vapor deposition process is described. The rotating Mo holder of $12 \mathrm{~mm}$ diameter and $6 \mathrm{~mm}$ height with the diamond substrate was heated by $2.45 \mathrm{GHz}$ microwaves to temperature about $800^{\circ} \mathrm{C}$ in the range of $(1.5-7) \% \mathrm{CH}_{4} / \mathrm{H}_{2}$ mixture to create plasma at pressure $70 \mathrm{Tr}$. Stabilization of the holder temperature was performed by optical observation of radiation from the holder followed by adjusting of the magnetron power. Diamond detectors are produced using microwave chemical vapor deposition process grown on single crystal diamond high pressure high temperature Sumimoto substrates, [100] oriented. The response of diamond detectors for X-rays has been measured in the current mode using medical X-rays tube. The linear response of the diamond detector current versus X-ray tube current (dose) is presented.
\end{abstract}

DOI: 10.12693/APhysPolA.127.1555

PACS: 52.75.-d, 81.15.Gh, 29.40.Vj, 07.85.Fv

\section{Introduction}

Diamond detectors for X-ray dosimetry are produced in different ways: using high-quality, single crystal chemical vapor deposition (CVD) diamond layers grown on high pressure high temperature (HPHT) [100] oriented substrates [1-3] or by application of single crystal CVD layers $[4,5]$. For X-ray dosimetry applications of the diamond polycrystal is also used [6]. In all above works the microwave CVD (MWCVD) process was used. However, thin polycrystalline diamond films $(10 / 20 \mu \mathrm{m})$ for diamond detectors are deposited by hot filament vapor deposition technique on metallic (tungsten) [5].

The aim of this paper is to present our low power MWCVD reactor and investigation of diamond detectors produced using this reactor [7-10].

\section{Low power microwave chemical vapor deposition reactor}

The MWCVD diamond is created in the following conditions: gas composition few percentage of hydrocarbons like $\mathrm{CH}_{4}, \mathrm{C}_{4} \mathrm{H}_{10}$ or $\mathrm{C}_{6} \mathrm{H}_{14}$ in $\mathrm{H}_{2}$, temperature about $800{ }^{\circ} \mathrm{C}$ and pressure $70 \mathrm{Tr}$. In these conditions

\footnotetext{
*corresponding author; e-mail: kord@slcj.uw.edu.pl
}

the gases are ionized into active radicals and diamond is created on the substrate ( $\mathrm{Si}$, tungsten, molybdenum, diamond substrate and other materials). The diagram of the reactor is presented in Fig. 1.

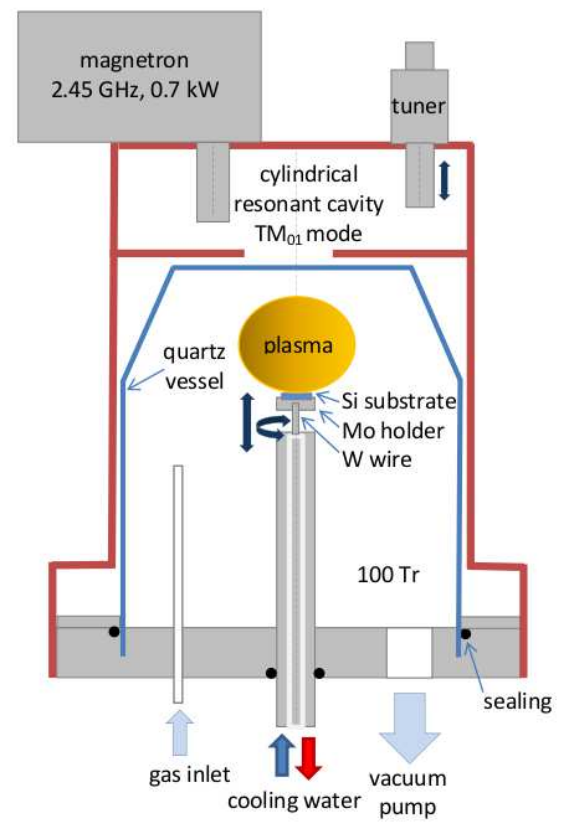

Fig. 1. MWCVD reactor. 
The cylindrical resonant cavity with web camera observing the Mo holder for temperature measurement is presented in Fig. 2. The visible vertical rift in the resonant cavity enables radiation observation from plasma and Mo holder by eye.

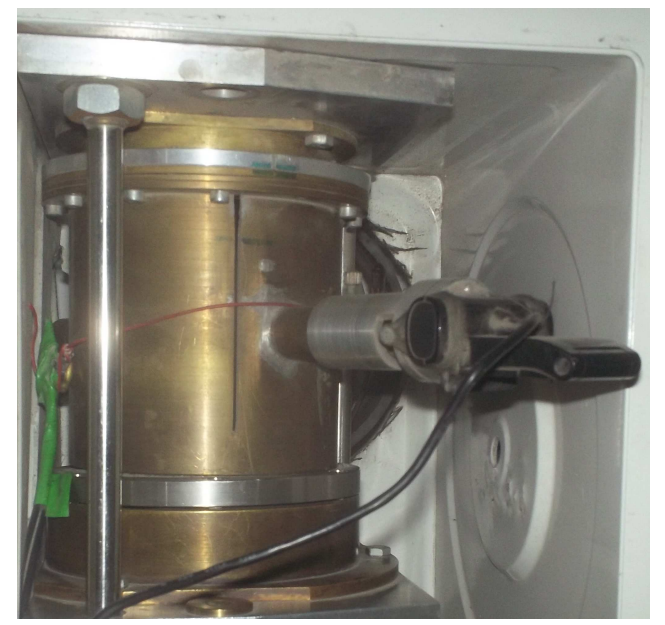

Fig. 2. Cylindrical resonant cavity of MWCVD reactor with Web Camera.

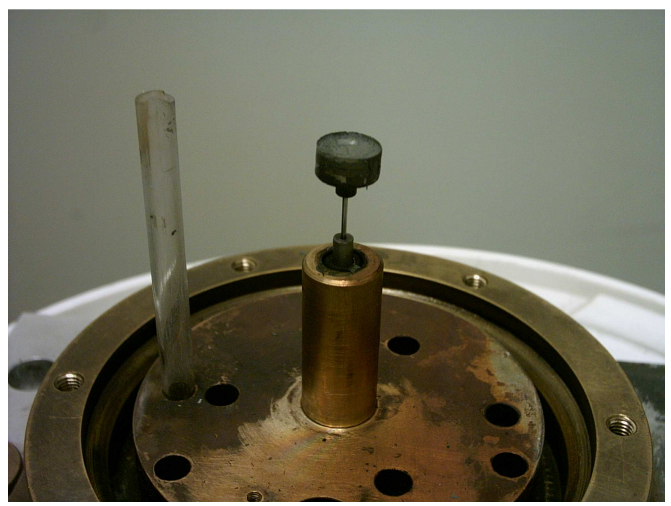

Fig. 3. Bottom of the chamber with Mo holder.

A photo of the Mo holder on the bottom of the chamber (quartz vessel and resonant cavity is removed) is presented in Fig. 3.

The Mo holder is supported by $1 \mathrm{~mm}$ diameter and $10 \mathrm{~mm}$ length tungsten wire to decrease the heat transfer from the warmed Mo holder to the bottom of the chamber. We used pulsed magnetron operating at $2.45 \mathrm{GHz}$ frequency with maximal power $0.7 \mathrm{~kW}$. The substrate is put into rotating Mo holder of diameter $12 \mathrm{~mm}$ and $6 \mathrm{~mm}$ high. In practical application the magnetron power of $300 \mathrm{~W}$ is sufficient to heat the Mo holder to temperature $800^{\circ} \mathrm{C}$. The holder is covered by quartz vessel of diameter $97 \mathrm{~mm}$ and $135 \mathrm{~mm}$ height. The vessel filled by methane and hydrogen mixture at pressure about $70 \mathrm{Tr}$ is located by the cylindrical resonant cavity operating at $\mathrm{TM}_{01}$ mode. The typical flows at pressure $70 \mathrm{Tr}$ of $\mathrm{CH}_{4}$ and $\mathrm{H}_{2}$ are $0.4 \mathrm{~cm}^{3} / \mathrm{s}$ and $5 \mathrm{~cm}^{3} / \mathrm{s}$, respectively. The speed of diamond layer growth is about $0.1 \mu \mathrm{m} / \mathrm{h}$.

Since the flow of gases is very low we used fermentation locks as flow-meters (which are commonly applied for registration carbon oxide in vine fermentation process) for measurement of $\mathrm{H}_{2}$ and $\mathrm{CH}_{4}$ flows by counting bubbles with fermentation locks filled by vacuum pump oil, see Fig. 4.

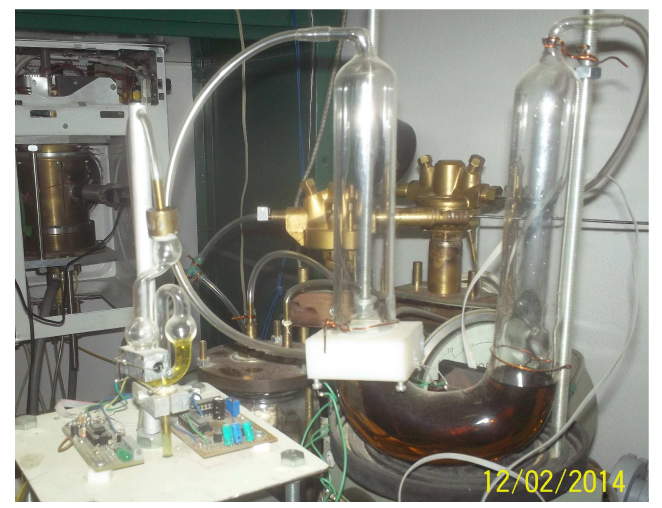

Fig. 4. Flow-meters based on the fermentation lock for methane (left) and for hydrogen (right).

The number of bubbles is counted by transoptors and sent to the computer system. Gas flow is proportional to the bubbles counting rate. Since the flow of hydrogen is about 100 times bigger than for methane therefore diameter of fermentation locks for hydrogen and methane is $35 \mathrm{~mm}$ and $8 \mathrm{~mm}$, respectively. To ensure precise measurements and calibration of flow-meters with gas bubbles we have used mechanical bellows flow-meters.

For gas pressure measurement we have used manometer with pressure-frequency converter based on the $\mathrm{RC}$ generator whose capacitance $\mathrm{C}$ changes its value as a function of the gas pressure.

Measurement of temperature is achieved by radiation registration from the hot Mo holder. For this purposes we have used plasma generation by pulsed magnetron supplied with AC frequency $50 \mathrm{~Hz}$. The plasma is generated when the $2.45 \mathrm{GHz}$ microwaves are emitted. For parts of the $50 \mathrm{~Hz}$ pulse when microwaves are stopped the thermal radiation is generated only by hot Mo holder without light radiation from the plasma. Using principles of web camera working where pixels are read in series rows by rows it is possible to register of pictures in time regions where plasma radiation is stopped and light is emitted only by hot holder (the method was proposed and elaborated by Tarasiuk). For proper temperature measurements the web camera is calibrated by the thermocouple.

Magnetron power regulation is adjusted by $\mathrm{AC}$ power supply in the range about $5 \mathrm{~V}$ with 7 bits precision, see Fig. 5.

Seven inductances with inductance proportional to $2^{n}$ are connected in series with magnetron and 


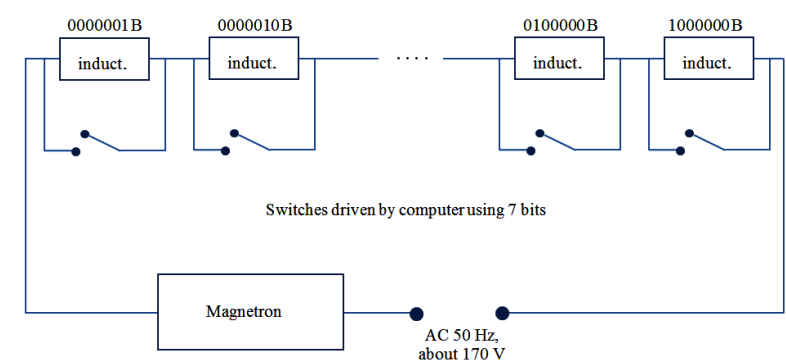

Fig. 5. Magnetron power regulation by adjusting of AC power supply in the range $5 \mathrm{~V}$ with 7 bits precision.

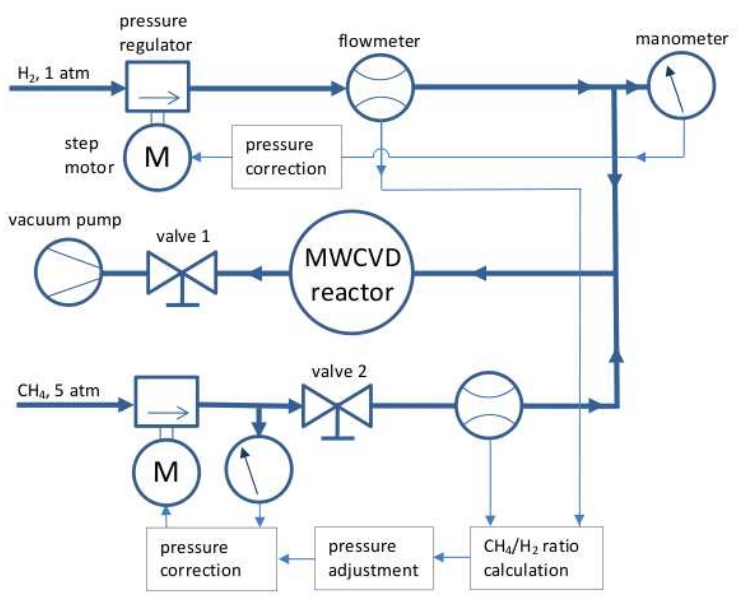

Fig. 6. Stabilization of $\mathrm{H}_{2}$ pressure and $\mathrm{CH}_{4} / \mathrm{H}_{2}$ gases ratio.

$50 \mathrm{~Hz}$ AC supply with voltage about 170 V. Each inductance can be closed or opened by relay driven by computer, depending on the Mo holder temperature needed. Stabilization of gasses pressure and gasses ratio in MWCVD reactor is presented in Fig. 6.

The pressure of pure hydrogen is decreased to about 70 Tr by pressure regulator controlled by manometer. The control unit named "pressure correction" stabilizes the assumed pressure of hydrogen by adjusting position of the pressure regulator using the step motor. Then hydrogen enters to the MWCVD reactor. The valve 1 before vacuum pump determines flow of the hydrogen which was selected to about $5 \mathrm{~cm}^{3} / \mathrm{s}$. The input methane pressure was decreased to about $150 \mathrm{Tr}$ by pressure regulator and its flow is limited by the valve 2 . The $\mathrm{CH}_{4} / \mathrm{H}_{2}$ ratio has been calculated using data from both flow-meters. Using these data the unit named "pressure adjustment" select a new pressure of methane which is executed by unit "pressure correction".

\section{Results}

The best diamonds detectors are produced using diamond single-crystals. Such crystals can be obtained by growing of diamond on single-crystal diamond HPHT substrates. For growing of diamond crystals we used
MWCVD process performed on our MWCVD reactor [710]. The synthetic single-crystal diamonds grown on the silicon substrate are randomly oriented due to the heteroepitaxy process, see Fig. 7.

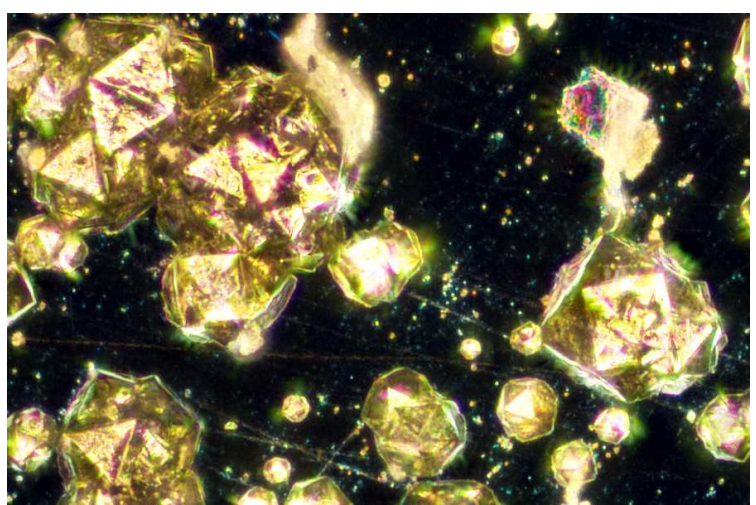

Fig. 7. Single-crystal diamonds are grown during 8 days on the silicon substrate using $2 \%$ concentration of butane in hydrogen at temperature about $800^{\circ} \mathrm{C}$ and pressure 70 torr. Randomly oriented diamond crystals of diameter about $0.2 \mathrm{~mm}$ are obtained in the heteroepitaxy process.

The MWCVD homoepitaxy process is performed on single-crystal Sumimoto $3 \times 3 \times 0.3 \mathrm{~mm}^{3}$ diamond substrate HPHT crystal, [100] oriented at temperature about $800^{\circ} \mathrm{C}$ and $1.4 \%$ of butane/hydrogen concentration with pressure $69 \mathrm{Tr}$. After 11 days of process the single-crystal diamonds, oriented with [100] direction in shape of square pyramids are obtained, see Fig. 8.

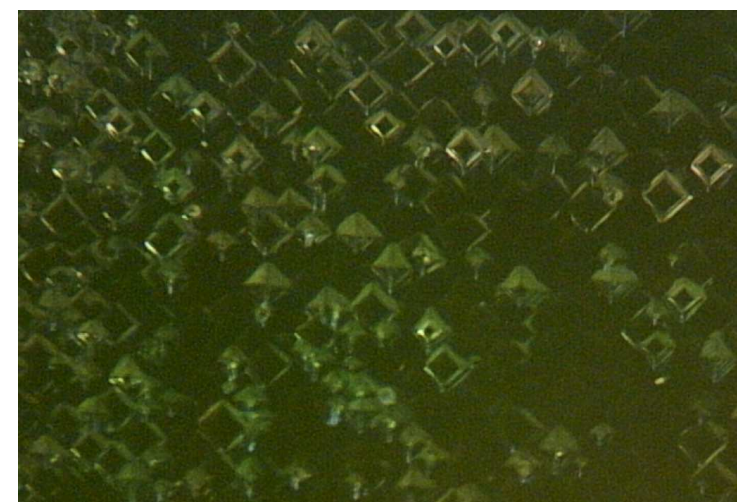

Fig. 8. Diamond [100] oriented single-crystals, grown by MWCVD in homoepitaxy process on [100] diamond Sumimoto substrate are obtained. Parallel oriented diamond square pyramids (some of them are without peaks) are visible.

After increasing concentration from $1.4 \%$ to $2.6 \%$ of butane/hydrogen with MWCD process lasted 4 days, the diamond layer of thickness $50 \mu \mathrm{m}$ was obtained, see Fig. 9.

Similar results were obtained with compositions of methane/hydrogen and hexane/hydrogen. 


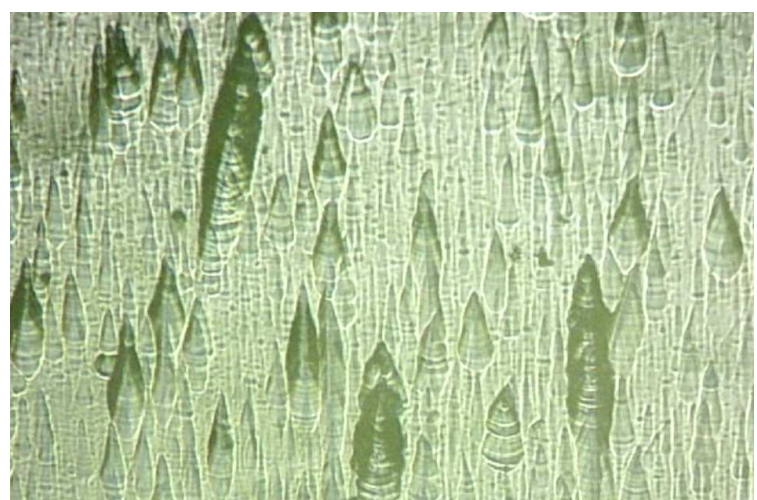

Fig. 9. Single-crystal diamond layer of thickness $50 \mu \mathrm{m}$ grown during 4 days by MWCVD homoepitaxy process on the $300 \mu \mathrm{m},[100]$ HPHT diamond single-crystal Sumimoto substrate.

\section{Test of diamond detectors}

The diamond detector has been prepared using $50 \mu \mathrm{m}$ CVD layer grown on single-crystal Sumimoto $3 \times 3 \times$ $0.3 \mathrm{~mm}^{3}$ diamond substrate HPHT crystal, [100] oriented using $\mathrm{CH}_{4} / \mathrm{H}_{2}$ mixture. For comparison we have build diamond detector using CVD diamond single crystal $2.6 \times 2.6 \times 0.3 \mathrm{~mm}^{3}$ [100] oriented, obtained from e6 company. The circular Al contacts of thickness about $2000 \AA$ were evaporated on both sides of the diamond CVD/HPHT and CVD plates. The thin wires are connected to the evaporated $\mathrm{Al}$ contacts by conductive thermally stabilized epoxy glue, see Fig. 10.

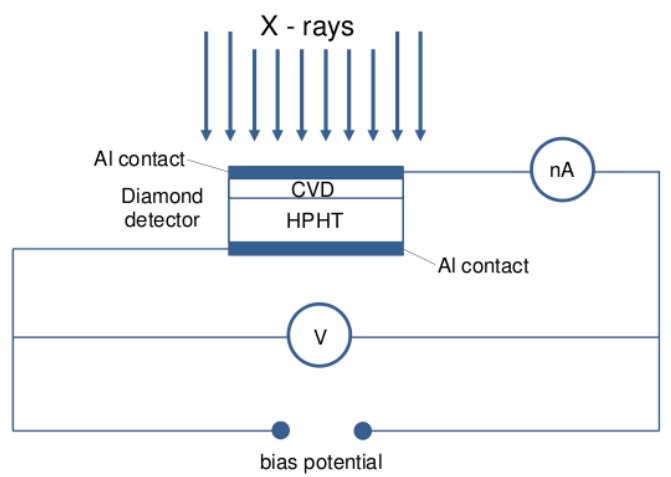

Fig. 10. Tests of diamond detectors in the current mode.

Diamond detectors have been tested using X-rays from medical Philips X-ray Tube Model 989000086101 with permanent filtration $2.6 \mathrm{~mm} \mathrm{Al}$ at Medical University of Warsaw, Warsaw, Poland. The X-ray tube operated at $40 \mathrm{kV}$. The dose strength at $1 \mathrm{~mm}^{2}$ of diamond detector was $2 \mathrm{~Gy} / \mathrm{s}$ for $10 \mathrm{~mA}$ of X-ray tube current. Measurements have been performed, in the current mode, see Fig. 10.

Response of diamond CVD/HPHT detector on X-ray tube operated at $40 \mathrm{kV}$ is shown in Fig. 11. The detector current is linear as a function on the $\mathrm{X}$-ray tube current (proportional to dose strength) for positive and negative detector bias polarization of about $\pm 200 \mathrm{~V}$.

Similar results are obtained for diamond detector of diameter $1.5 \mathrm{~mm}$ made from CVD diamond single crystal obtained from e6 company, see Fig. 12.

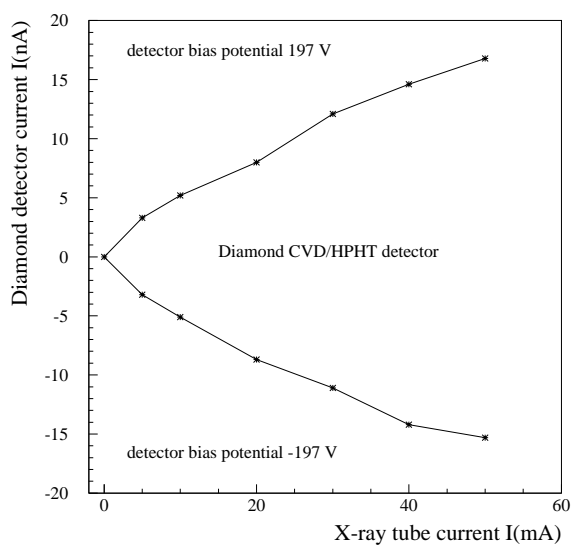

Fig. 11. Response of diamond CVD/HPHT detector for X-ray fluence generated by X-ray tube current.

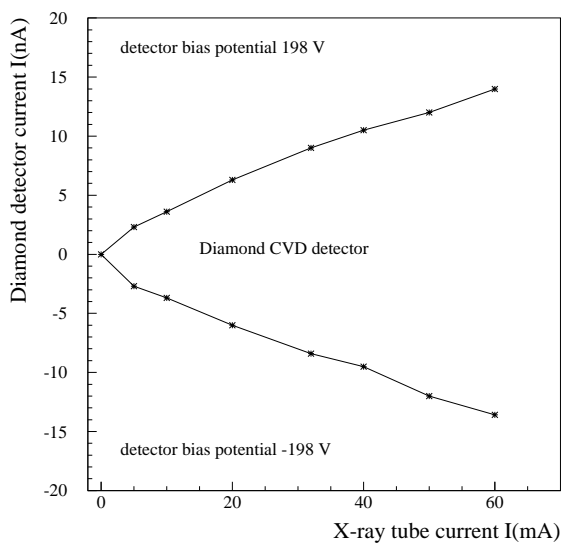

Fig. 12. Response of diamond CVD detector for X-ray fluence generated by X-ray tube current.

Almost symmetrical response of diamond detector for positive and negative bias polarizations confirms that diamond detectors are produced from isolating material.

Obtained linear response of diamond detectors versus $\mathrm{X}$-ray dose strength gives possibility to use such detectors in X-rays dosimetric applications.

\section{Acknowledgments}

We would like to express our great appreciation to Dr. Krzysztof Sudlitz for collaboration in preparation of CVD reactor.

This work was supported by the National Science Centre of Poland Grant No. N N202 031640. 


\section{References}

[1] A. Balducci, Y. Garino, A. Lo Guidice, C. Manfredotti, M. Marinelli, G. Pucella, G. Verona-Rinati, Diam. Relat. Mater. 15, 1044 (2007).

[2] H. Matsubara, Y. Saitoch, O. Maida, T. Teraji, K. Kobajaschi, T. Ito, Diam. Relat. Mater. 16, 797 (2006).

[3] C. Descamps, D. Tromson, N. Tranchant, A. Isambert, A. Bridier, C. De Angelis, S. Onori, M. Pucciolini, P. Bergonzo, Radiat. Measur. 43, 933 (2008).

[4] G.T. Betzel, S.P. Lansley, F. Baluti, L. Reinsch, J. Meyer, Nucl. Instrum. Methods Phys. Res. A 614, 130 (2010).

[5] C. Manfredotti, P. Polesello, M. Truccati, E. Vittone, A. Lo Guidice, F. Fizotti, Diam. Relat. Mater. 7, 523 (1998).

[6] M. Assiamach, T.L. Nam, R.J. Keddy, Appl. Radiat. Isotopes 65, 545 (2007).

[7] A.J. Kordyasz, K. Sudlitz, E. Kulczycka, M. Antczak, A. Bednarek, M.S. Figat, B. Filipiak, A.P. Jakubowski, P. Jasinski, M. Kopka, M. Kowalczyk, P. Krysiak, K. N. Labeda, Z.C. Morozowicz, A. Pietrzak, R. Pozorek, University of Warsaw Heavy Ion Laboratory Annual Report 2007, SLCJ, Warsaw 2008, p. 47.
[8] A.J. Kordyasz, K. Sudlitz, E. Kulczycka, M. Antczak, A. Bednarek, M.S. Figat, B. Filipiak, A.P. Jakubowski, P. Jasinski, M. Kopka, M. Kowalczyk, P. Krysiak, K. N. Labeda, Z.C. Morozowicz, A. Pietrzak, R. Pozorek, University of Warsaw Heavy Ion Laboratory Annual Report 2008, SLCJ, Warsaw 2009, p. 40.

[9] A.J. Kordyasz, M. Kowalczyk, J. Tarasiuk, A. Bednarek, S. Przywozka, B. Majerowski, B. Piatkowski, R. Tarnowski, University of Warsaw Heavy Ion Laboratory Annual Report 2012, SLCJ, Warsaw 2013, p. 64.

[10] A.J. Kordyasz, M. Kowalczyk, J. Tarasiuk, A. Bednarek, B, Radomyski, L. Kordyasz, University of Warsaw Heavy Ion Laboratory Annual Report 2013, SLCJ, Warsaw 2014, p. 81. 